\title{
Work in Progress - An Equity Bifocals Framework for University Makerspaces
}

\section{Wendy Roldan, University of Washington}

Wendy is a second-year PhD student in Human Centered Design and Engineering at the University of Washington studying the development of equitable engineering education. Her work draws from the fields of engineering education, design, and learning sciences.

\section{Dr. Jennifer A. Turns, University of Washington}

Jennifer Turns is a Professor in the Department of Human Centered Design \& Engineering at the University of Washington. She is interested in all aspects of engineering education, including how to support engineering students in reflecting on experience, how to help engineering educators make effective teaching decisions, and the application of ideas from complexity science to the challenges of engineering education. 


\title{
WIP: Practice-Facing Equity Bifocals for University Makerspaces
}

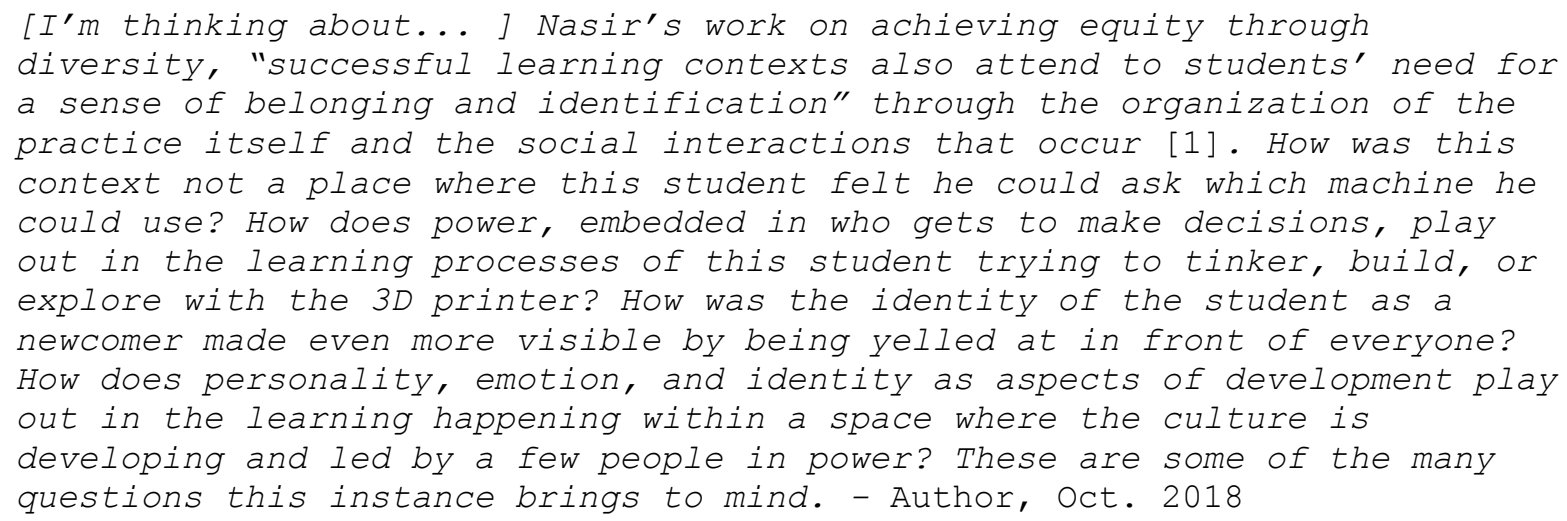

\section{Background and Motivation}

We have been engaged in ethnographic field work in university makerspaces for the past two years. The passage above is from field notes that document our initial connections between sociocultural theories on equity and the practices we were observing in the makerspace. As we wrote this memo, we used Nasir's work as a guide toward crafting the kinds of questions that called attention to the things that felt significant in our observations. We notice that the literature guiding our understanding of equity in makerspaces is usually situated in the context of K-12 education and not oriented toward the design of university makerspaces. Thus, this paper offers an in-progress, practice-facing equity bifocals framework to help us: (a) make sense of the questions we come to when conceptualizing equity in university makerspaces and (b) name the design tensions present in university makerspaces.

The motivation for this work is based on the rapidly growing makerspace movement on university campuses with the simultaneous shift in enrollment of students from underrepresented groups in engineering degrees across the United States. How we conceptualize equity within makerspaces and in the field of engineering education is important as we engage in efforts to attract, retain, and sustain the success of students from non-dominant groups in engineering. But, conceptualizing equity within university makerspaces is an ongoing, large ask. We argue that we must first name the design tensions present in university makerspaces, to best position ourselves toward the design and implementation of equitable interventions in university makerspaces.

\begin{abstract}
Approach
There exists a rich amount of literature on equity in makerspaces within the learning sciences community, but often it is situated in K-12 educational spaces [2]-[4]. Within the engineering education community, scholarship on equity exists [5] but is not often situated as a central research goal in makerspace research [6]-[8]. One body of generous scholarship on university makerspaces highlights the promise of makerspaces for engineering education [9], including opportunities to promote a growth mindset [10], to support community development as spaces run by students [8], and to develop leadership characteristics [11]. Often publications within this body of work conclude with calls to action to carefully consider the audience and who is included in the maker movement. It seems that another body of scholarship on makerspaces critically calls attention to the practices of makerspaces which may be inequitable. However, makerspace practitioners rarely engage or are engaged
\end{abstract}


in this type of work. There is an opportunity to bring together the generous and the critical to support the design of more equitable university makerspaces.

Different stakeholders within engineering education have different definitions of equity which are drawn from their lived experiences. The purpose of our framework is not to put forth a definition of equity we believe everyone should use, rather we believe the framework can help us structure conversations on equity in makerspaces through a shared understanding. Against this backdrop, our research is informed by Vossoughi et al.'s definition: “... equity lies in the how of teaching and learning: specific ways of designing making environments, using pedagogical language, integrating students' cultural and intellectual histories, and expanding the meaning and purposes of STEM learning" [12].

While the focus of this WIP is not meant to be tied to the details of the university makerspaces we observed, here we offer some details on the makerspaces that were a part of this research. Our field work is with two university makerspaces both situated in different residential living spaces within a large research institution in the West Coast. The first author has been engaged in field work for two years with Makerspace A and for one year with Makerspace B, while maintaining an ongoing partnership with the makerspaces' student and full-time staff. The nature of our research site is unique because after almost four years of Makerspace A being fully operational, it became a model for the university to build Makerspace B which is 10 times larger than Makerspace A (in terms of square feet). Makerspace A and B are about 20 minutes away from each other. The college of engineering supports both makerspaces and engineering courses are regularly taught in spaces. Both makerspaces feature common tools found in a makerspace like laser cutter, 3D printers, Carvey machines, vinyl cutter, sewing and embroidery stations, and soldering stations. Both makerspaces center student-staff and regularly offer introductory workshops on the tools in the space. Some examples of workshops offered in these spaces include laser cutting business cards, engraved mugs, and 3D printing basics.

\section{Contribution}

We propose an in-progress, practice-facing equity bifocals framework (Figure 1) to help the engineering education community conceptualize equity in university makerspaces. We then provide one detailed illustration (using data from our ethnographic fieldwork) that exemplifies how we might use the framework to (a) identify generous and critical interpretations of a makerspace and (b) discuss design tensions as seen in Table 1.

Framework. The first component of the framework is the perspective of equity [1], [12]. As we strive to design makerspaces where all participants can reach their full academic potential, we call attention to the value of becoming attuned to seeing practices and wrestling with how we might make sense of them through the metaphor of bifocals. The second component of our equity bifocals calls attention to both the generous as we honor the hard work that makerspace practitioners are already doing and the critical as we strive to design more equitable makerspaces. We then draw on the notion of a design tension, which does not identify a problem or a solution but rather refers to "a limited resource or choice across one or more criteria" [13]. The notion of design tensions helps us see university makerspace design decisions as situated within a larger structure of student experiences, stakeholder perspectives, and pragmatic possibilities. By taking a design approach we are better able to see what is and imagine what could be. An equity bifocals framework can help those 
interested in exploring equity within engineering education to both see more clearly what is going on in university makerspaces (honoring the work through a generative lens) and make sense of the questions we still have to address in the ongoing effort to design equitable makerspaces (proposing future action through a critical lens). We offer this practice-facing framework while being cognizant of existing efforts makerspace practitioners are currently engaging in to promote equity.

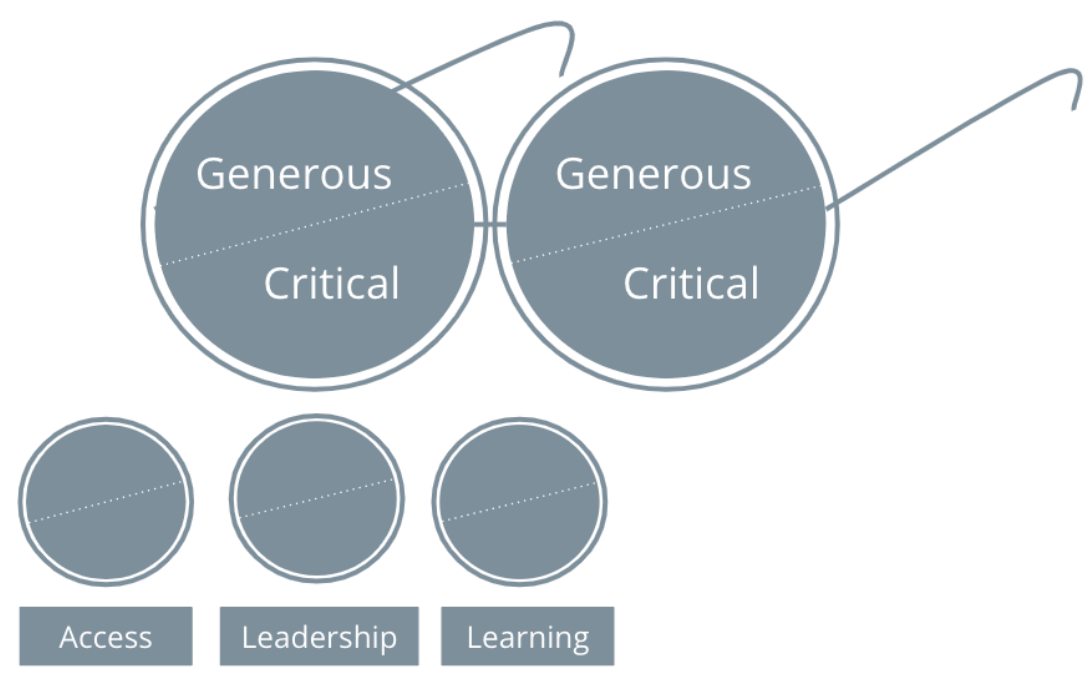

Figure 1. Equity bifocals as an analytical approach

\begin{tabular}{|c|c|c|c|}
\hline $\begin{array}{l}\text { Makerspace } \\
\text { Aspect }\end{array}$ & $\begin{array}{l}\text { Generous } \\
\text { Interpretation }\end{array}$ & $\begin{array}{l}\text { Critical } \\
\text { Interpretation }\end{array}$ & $\begin{array}{l}\text { Design } \\
\text { Opportunity }\end{array}$ \\
\hline Access & $\begin{array}{l}\text { Safety and } \\
\text { accountability }\end{array}$ & Exclusionary & \multirow{3}{*}{$\begin{array}{l}\text { Navigating design } \\
\text { tensions to } \\
\text { identify existing } \\
\text { practices as assets } \\
\text { or opportunity for } \\
\text { growth }\end{array}$} \\
\hline Leadership & $\begin{array}{l}\text { Student- } \\
\text { centered model }\end{array}$ & Networking & \\
\hline Learning & $\begin{array}{l}\text { Self-directed } \\
\text { learning }\end{array}$ & Lonely & \\
\hline
\end{tabular}

Table 1. A generous and critical interpretation of three university makerspace aspects

Illustration. Makerspaces, as sites of learning within engineering education, provide opportunities for new learning models such as self-directed learning. Makerspaces can provide students with the chance to become self-taught, to explore a concept they have been curious about, and to discover new topics. One generous interpretation of self-directed learning in university makerspaces is that it offers students a space where there is not an expert lecturing to everyone. One field note jotting that supports this generous read is:

Field note \#9684: The tables and sitting area were grouped, encouraging team effort and peer evaluation and assistance. When sitting side by side or across from another student, learners are encouraged to discuss and ask questions from each other rather than being dependent on the expert. 
Here, we notice an existing practice of the makerspace where tables are situated in a way that encourages collaboration and assistance across peers. Our practice-facing equity bifocals framework helps us making sense of this observation with an eye toward equity. One critical interpretation of the self-directed learning model is that it may feel lonely. Students who desire to learn about a topic could feel a lack of direction on where to start. Makerspaces, with the tools and people present, allow for students to explore a topic they may be interested in. Implicitly with this freedom may come the feeling of being unsupported or alone. In one of our field notes, we documented an observation of a student working in the space:

Field note \#9: ...there was someone working for a while. She seemed to be familiar with the space, both because David didn't ask her if she needed help and also because she was going back and forth from the machines to her work station.

This instance provokes us to think more about who is collaborating in the space, who feels comfortable asking for assistance, and how might we support those who enjoy working alone? The two observations we offer as examples above are starting points for thinking generously and critically about aspects of learning and equity within makerspaces.

From these observations, we might ask what if a student needed help but did not feel comfortable asking for help given the learning norms of the space? The design tension can be seen as a choice across criteria of supporting self-directed learning while recognizing that learning does not happen alone. By exploring this design tension through the lens of our practice-facing equity bifocals framework, we are better equipped to design learning opportunities that draw from the strength of different learning models while mitigating against potential pressures students have to work and learn alone in the makerspace.

\section{Significance}

If we have (as we do) a goal of proposing ways in which issues of equity might be addressed in makerspaces, it is helpful to first have a framework to guide our efforts. The in-progress, practice-facing equity bifocals framework we introduce in this work could help the engineering education community work from a similar language when discussing equity strategies, decisions, and implications in a university makerspace. We propose that with this practice-facing equity bifocals framework we are better equipped to make more judicious and intentional decisions in the design of university makerspaces as we seek ways of improving spaces to be more equitable.

The design challenge becomes how might we keep the positive implications of generous interpretations, while mitigating the negative implications that come with a critical interpretation that may cause inequities for students? In addressing this design challenge, we do not aim to find a balance between the two but propose a negotiation. Just as equity does not mean equality, a call for balance is insufficient as we strive to include more people in our spaces.

By taking an equity bifocal lens we are able to engage in: (a) naming the design tensions present in a university makerspace, while (b) honoring the contributions of makerspace participants and leadership in a generous light, and also (c) naming the critical as we seek to improve our spaces. Now, we ask what does it mean for others to put on their bifocals with slightly different views of equity? This journey toward equitable makerspaces is a collaborative effort with stakeholders who might have different views of equity [3] and this needs to be acknowledged. By naming the 
kinds of equity issues that are at play through an equity bifocals framework, we might be better prepared to improvise and have impact on equity in makerspaces.

We end on a hopeful note as we engage in future work around equity and makerspaces. Building on the works of feminist scholars, we highlight collaborative, passionate reconstruction around the way we think about the future of university makerspaces. We propose further collaboration among stakeholders not yet considered and a call to action to stay with the trouble [14] of the difficult task that is conceptualizing equity within university makerspaces.

\section{References}

[1] N. S. Nasir, A. S. Rosebery, B. Warren, and C. D. Lee, "Learning as a Cultural Process: Achieving Equity Through Diversity.," in The Cambridge handbook of: The learning sciences., New York, NY, US: Cambridge University Press, 2006, pp. 489-504.

[2] S. Vossoughi, P. K. Hooper, and M. Escudé, "Making Through the Lens of Culture and Power: Toward Transformative Visions for Educational Equity," Harv. Educ. Rev., vol. 86, no. 2, pp. 206-232, Jun. 2016.

[3] F. Barajas-López and M. Bang, "Indigenous Making and Sharing: Claywork in an Indigenous STEAM Program," Equity Excell. Educ., vol. 51, no. 1, pp. 7-20, Jan. 2018.

[4] A. C. Barton, E. Tan, and D. Greenberg, "The makerspace movement: Sites of possibilities for equitable opportunities to engage underrepresented youth in STEM," Teach. Coll. Rec., 2016.

[5] A. Pawley, J. Mejia, and R. Revelo, "Translating Theory on Color-blind Racism to an Engineering Education Context: Illustrations from the Field of Engineering Education," presented at the ASEE annual conference \& exposition proceedings, 2018.

[6] N. Taylor, U. Hurley, and P. Connolly, "Making community: the wider role of makerspaces in public life," presented at the Proceedings of the 2016 CHI Conference on Human Factors in Computing Systems, 2016, pp. 1415-1425.

[7] A. Noel, L. Murphy, and A. Jariwala, "Sustaining a diverse and inclusive culture in a student run makerspace," presented at the Proceedings of the ISAM conference, 2016.

[8] S. Weiner, M. Lande, and S. S. Jordan, "What Have We" Learned" from Maker Education Research? A Learning Sciences-base Review of ASEE Literature on the Maker Movement," presented at the ASEE Annual Conference and Exposition, Conference Proceedings, 2018, vol. 2018.

[9] V. Wilczynski, A. Wigner, M. Lande, and S. Jordan, "The Value of Higher Education Academic Makerspaces for Accreditation and Beyond," Plan. High. Educ., vol. 46, no. 1, pp. 32-40, 2017.

[10] L. Martin, “The promise of the maker movement for education," J. Pre-Coll. Eng. Educ. Res. J-PEER, vol. 5, no. 1, p. 4, 2015. 
[11] J. Oplinger, M. Lande, S. Jordan, and L. Camarena, "Making Leaders: Leadership Characteristics of Makers and Engineers in the Maker Community.," Am. J. Eng. Educ., vol. 7, no. 2, pp. 65-82, 2016.

[12] S. Vossoughi, M. Escudé, F. Kong, and P. Hooper, "Tinkering, learning \& equity in the after-school setting," presented at the annual FabLearn conference. Palo Alto, CA: Stanford University, 2013.

[13] D. Tatar, "The design tensions framework," Human-Computer Interact., vol. 22, no. 4, pp. 413-451, 2007.

[14] D. Haraway, "When species meet: Staying with the trouble," Environ. Plan. Soc. Space, vol. 28, no. 1, pp. 53-55, 2010. 